\title{
Psychosocial Correlates of the Short-Form-36 Multidimensional Health Survey in University Students
}

\author{
M. Scott DeBerard' ${ }^{1}$ Kevin S. Masters ${ }^{2}$ \\ ${ }^{1}$ Department of Psychology, Utah State University, Logan, USA \\ ${ }^{2}$ Department of Psychology, University of Colorado Denver, Denver, USA \\ Email: scott.deberard@usu.edu, kevin.masters@ucdenver.edu
}

Received 8 January 2014; revised 5 February 2014; accepted 1 March 2014

Copyright (C) 2014 by authors and Scientific Research Publishing Inc.

This work is licensed under the Creative Commons Attribution International License (CC BY).

http://creativecommons.org/licenses/by/4.0/

(c) (i) Open Access

\begin{abstract}
Stress, social support, and coping correlates of the Short-Form 36 Health Survey (SF-36) were examined in 307 undergraduate students. Instruments included the SF-36, the Perceived Stress Scale, the Multidimensional Scale of Perceived Social Support, and the Ways of Coping Inventory-Revised. HRQOL appeared worse and reported stress and use of maladaptive coping strategies were higher than age-appropriate national norms. Stress, social-support, and coping strategies were correlated with SF-36 physical and mental health subscales. In a stepwise multiple regression equation predicting the SF-36 Mental Health Composite Scale, stress, escape-avoidance coping, problem-focused coping, and accepting-responsibility coping emerged as significant predictors. In another stepwise multiple regression equation predicting the SF-36 Physical Composite Scale, self-control coping and family support emerged as significant predictors. Results suggest that psychosocial measures are excellent predictors of mental HRQOL but are not as strong for physical HRQOL. Possible interventions for improving health status among college students are offered.
\end{abstract}

Keywords

Health-Related Quality of Life, Psychosocial Correlates

\section{Psychosocial Correlates of Health-Related Quality of Life in University Students}

In 1948 the World Health Organization defined health as "a state of complete physical, mental, and social wellbeing and not merely the absence of disease or infirmity (WHO) (World Health Organization, 1948). This definition has been embraced by health researchers and increasingly medical and disease outcomes are expressed in such multidimensional terms (Kaplan, 1990; Ware, 2000). One phrase that summarizes this complex approach to assessing health status is health-related quality of life (HRQOL). HRQOL has been defined as a subjective sense of physical, mental, and social well-being and this general construct has been operationalized in a number of 
self-report instruments (Haas, 1999; Stewart \& Ware, 1992; Ware, Snow, Kosinski, \& Gandek, 2000). One of the most reliable and well-validated methods for assessing HRQOL is the Short-Form 36 (SF-36; Stewart \& Ware, 1992; Ware, 2000). This measure was created by the Rand Corporation in the 1980's and has been widely used as a measure of HRQOL. It has been used extensively in characterizing outcomes from a variety of medical interventions (DeBerard, Masters, Colledge, Schleusener, \& Schlegel, 2001; Gross, Limwattananon, Matthees, Zehrer, \& Savik, 2000; Matsen, Antoniou, Rozencwaig, Campbell, \& Smith, 2000; Rumsfeld et al., 1999), assessing general health status of inpatient and outpatient samples, and in assessing general population health functioning via epidemiologic studies (Stewart \& Ware, 1992; Ware et al., 2000). The SF-36 has been particularly useful in assessing HRQOL across many different chronic disease populations including, for example, patients with multiple sclerosis (Arnoldus et al., 2000), HIV-AIDS (Bastardo \& Kimberlin, 2000), gastroesophageal reflux disease (Farup et al., 2001), and back pain (Bombardier, 2000).

One group for which SF-36 normative data are not existent is the college student population. Colleges and universities are increasingly interested in assessing and understanding HRQOL of their students, although this interest has resulted in only a few empirical studies (Damush, Hays, \& DiMatteo, 1997; Roberts et al., 2000; Roberts, Golding, Towell, \& Weinreb, 1999); none of which have utilized the SF-36 as a measure of HRQOL in an American sample.

Documentation of American college student norms for the SF-36 would be useful for academic administrators in establishing HRQOL benchmarks, aid in recruitment of future students, and in understanding how curricular or extracurricular factors might influence HRQOL. This information will likely also be relevant for clinicians who work with college student populations in terms of identification of students who are at high risk for experiencing poor quality of life during their college years.

In addition to the paucity of research in college student HRQOL, little research has addressed correlates of HRQOL, particularly those correlates which might be related to worse health status and which are potentially modifiable through psychosocial intervention. This study examined three psychosocial constructs that may have predictive implications for HRQOL as assessed by the SF-36. These constructs include stress, social support, and ways of coping with stressful situations.

Measures of stress have been shown to correlate with a wide array of poor health outcomes (Cohen et al., 1998; Cohen, Kamarck, \& Mermelstein, 1983; Glaser, Kiecolt-Glaser, Speicher, \& Holliday, 1985; Tennant, 2000). Nevertheless, there are no studies looking at correlations of stress and the SF-36 within a college student population. It is expected that higher levels of stress should be related to poorer SF-36 health status. Social support is another psychosocial variable that has been widely studied in medical literature and its effects on overall health functioning are generally beneficial. For example, social support has been shown to slow disease progression (Blumenthal et al., 1987; Leserman, 2000) facilitate rehabilitation following surgical intervention (Hamalainen et al., 2000) and improve immune system function (Kennedy, Kiecolt-Glaser, \& Glaser, 1988). It is expected that lower levels of social support should be related to poorer SF-36 health function, although this assertion has never been examined in a college student population.

Coping has also been studied extensively in the medical and health literatures and it appears that certain adaptive coping strategies (e.g., problem-focused coping) might have beneficial effects on health status (Lee et al., 2000) while maladaptive coping strategies (e.g., avoiding the problem) have negative effects on health status (Drossman et al., 2000; Frazier, 2000; Moskovitz, Maunder, Cohen, McLeod, \& MacRae, 2000). It is expected that adaptive coping strategies should be related to better SF-36 health status while maladaptive coping strategies should be related to poorer SF-36 health status dimensions. In summary, it is asserted that poorer student HRQOL will be related to high perceived stress, low levels of social support, and the use of maladaptive coping strategies.

The present purpose was to examine these predictions in a sample of college students. This study examined two research questions: 1) What are the mean scores for the SF-36 scales and for measures of psychosocial functioning among a college student sample and how do they compare with appropriate non-collegiate national norms? and 2) Can Mental and Physical HRQOL as assessed by the SF-36 be predicted via perceived stress, social support, and coping measures?

\section{Method}

\subsection{Participants}

Participants included 307 undergraduate students, solicited from introductory psychology and sociology classes 
at a private Pacific Northwest University. There were 211 women (68.7\%) and the mean age for the sample was 19.4 years ( $\mathrm{SD}=1.2$ ), with a range from 18 to 26 years. In terms of ethnicity, $83 \%$ were Caucasian, $7.3 \%$ were Asian-American, $2.3 \%$ were Hispanic, $1.3 \%$ were African-American, .3\% were Native-American, and 5.5\% were "Other." Respondents did not receive incentives for participation.

\subsection{Procedure}

This research protocol was approved by the University's Institutional Review Board. A packet of questionnaires was administered to participants during the last 30 minutes of a class period. Average class size was 30 students and surveys were completed during the first week of classes. A cover sheet informed students that the purpose of the study was to examine attitudes and opinions regarding a wide range of topics and that the individual data they provide would be kept confidential. The cover sheet also noted that subjects could choose to not participate or discontinue the survey at any time. Participants signed a consent slip if they agreed to complete the survey. Subjects completed all the following inventories based upon their previous months' functioning.

\subsection{Instrumentation}

Four scales were included. The Short-Form Health Survey-36 (SF-36) is a 36-item general health survey that was used to assess eight general subjective dimensions of physical and mental health-related quality of life (Ware, 1994; Ware et al., 2000). The eight distinct health dimensions assessed by this measure include: a) Physical Functioning (PF): extent to which health interferes with performance of a variety of behavioral activities (e.g., sports, carrying groceries, climbing stairs, and walking); b) Role-Physical (RP): extent to which health interferes with usual daily activities such as work, housework, or school; c) Bodily Pain (BP): intensity of bodily pain during last month and extent to which it interferes with normal work; d) General Health (GH): current evaluation of personal health; e) Vitality (VT): degree to which a person feels full of pep and energy or worn out and tired; f) Social Functioning (SF): extent to which health interferes with normal social activities like visiting friends during the past month; g) Role-Emotional (RE): degree to which emotional problems resulted in problems with work or daily function; and h) Mental Health (MH): degree to which a person feels nervous and depressed. Median internal consistency coefficients for the SF-36 subscales across 14 studies equal or exceed 80 with the exception of the Social Functioning subscale (median $=.76$ ). Construct validity of this instrument has been established via multitrait scaling analyses (Ware et al., 2000) and concurrent validity has been demonstrated in studies showing the relationship between instrument scores and chronic medical conditions (Stewart \& Ware, 1992; Ware et al., 2000).

Authors of the SF-36 indicate that the eight subscales may be aggregated into Mental Health (MCS) and Physical Health (PCS) Component Summary scales (Ware, 1994). These summary scales capture $80-85 \%$ of the variance in the eight SF-36 scales and allow researchers to perform statistical analyses on two higher-order constructs (MCS/PCS) rather than separate analyses for each of the eight SF-36 subscales. A standardized method for calculating the MCS and PCS scales is available (Ware, 1994) and these procedures were utilized in the present study. The authors of the SF-36 report coefficient alphas of .88 and .93 for the MCS and PCS, respectively. The authors also note that the PF, RP, and BP scales have excellent validity as measures of physical health status while the MH, RE, and SF scales have substantial validity for assessing mental health (Stewart \& Ware, 1992; Ware, 1994; Ware et al., 2000). The VT and GH scales are sensitive to both physical and mental health components (Stewart \& Ware, 1992; Ware, 1994; Ware et al., 2000).

The Perceived Stress Scale-10 (PSS) is a 10-item measure which assesses the degree to which individuals find situations in their lives to be stressful (Cohen \& Williamson, 1988). The PSS is designed to assess the degree to which a stressful experience is perceived as unpredictable and uncontrollable and the degree to which a person feels overloaded as a result (Cohen \& Williamson, 1988). Each item is rated on a 5-point Likert scale $(0=$ never to 4 = very often). Examples include: "In the last month, how often have you been upset because of something that happened unexpectedly?"; "In the last month, how often have you felt that you were unable to control the important things in your life"; and "In the last month, how often have you felt that you were on top of things." The PSS subscales have been shown to have adequate internal consistency (Alpha $=.84$ to .86 ) and good two-day test-retest reliability (.85) (Cohen \& Williamson, 1988). The PSS has evidence of concurrent and construct validity via moderate correlations with life event scales (.32) (Cohen \& Williamson, 1988).

Social support was assessed with the Multidimensional Perceived Social Support Scale (MPSSS; Dahlem, 
Zimet, \& Walker, 1991; Zimet, Dahlem, Zimet, \& Farley, 1988). The MPSSS is a 12-item scale employing a 7point Likert-type format ( 1 = very strongly disagree; 7 = very strongly agree). A total score and three factor analytically derived subscales reflecting perceived social support from family, friends, and significant others are obtained. The author's report coefficient alphas for the subscales ranging from .85 to .91 and test-retest correlations ranging from .75 to .85 (Dahlem et al., 1991; Zimet et al., 1988).

The Ways of Coping Checklist-Revised (WOC) is a 66-item self assessment inventory designed to assess cognitions and behaviors people use in dealing with stressful life events or situations (Folkman \& Lazarus, 1988). Based upon factor analysis, eight scales were developed including: Confrontive Coping: aggressive-hostile efforts to change situations; Distancing: cognitive efforts to detach oneself from stressful situations; SelfControlling: keeping to yourself and minimizing feelings; Seeking Social Support: efforts to seek tangible, emotional, or informational support from others; Accepting Responsibility: blaming yourself for problems and using efforts to correct situations; Escape-Avoidance: wishful-thinking that problem would go away and using efforts to escape or avoid problems; Planful Problem Solving: planned-analytic and focused efforts to solve problems; and Positive Reappraisal: focusing on positive aspects of dealing with stressors. The coefficient alphas for the subscales range from .61 for the Distancing subscale to .79 for the Positive Reappraisal subscale and the authors report strong theoretical and empirical support for the construct validity of this measure (Folkman \& Lazarus, 1988).

\section{Results}

Table 1 contains the means and standard deviations for the student sample and comparative normative samples for the psychosocial and SF-36 measures (see Table 1).

An effect size calculation was completed for each comparison and is presented in the far right column. Large effect sizes (>.80) were evident for total perceived stress scale and for all 8 coping subscales when comparing the present student sample with comparable normative samples. It appears that the students in this sample reported a greater experience of stress and engaged more frequently in all types of coping than did comparative normative groups. Small (.20 - .49), but interpretable, effect sizes were achieved for the MPSSS scales, with the exception of the Significant-Others Subscale. Thus, students reported perceiving more social support from family and friends than the normative sample. Small negative effect sizes were calculated for the following SF-36 subscales: Pain Severity, Vitality, Role-Emotional, Mental-Health and the Mental Health Component Summary Scale. These data suggest that across these domains, students experienced worse HRQOL than an age-appropriate normative sample.

To assess whether perceived stress, social support, and coping could predict HRQOL two separate stepwise-entry linear regressions were calculated for the two composite scales of the SF-36, i.e., the Physical (PCS) and the Mental Health (MCS) Component Summary Scales. These two scales were used because they adequately represent, at a general level, the specific constructs measured by the other scales and by using only two scales the number of regressions calculated was reduced. This reduction increased clarity of interpretation and reduced the likelihood of type 1 error.

The regression using the psychosocial variables as predictors of the MCS was significant $(\mathrm{F}(4,302)=79.41$, $p=.000, \mathrm{R}=.72$; see Table 2). Examination of the individual variables indicates that this finding was largely due to the influence of perceived stress (negative relation) along with escape-avoidance coping (negative relation). Planful problem solving (positive relation) and accepting responsibility (negative relation) coping were less potent contributors. The regression using the psychosocial variables as predictors of the PCS was also significant $(\mathrm{F}(2,304)=5.997, p=.005, \mathrm{R}=.20$; see Table 3$)$. Examination of the individual variables indicates that this finding was due to the influence of accepting responsibility coping (positive relation), self-controlling coping (negative relation), and family social support (positive relation).

\section{Discussion}

The major findings of this study are: 1) this sample of college students demonstrated higher levels of perceived stress, greater use of all measured coping strategies (both beneficial and maladaptive), slightly greater overall social support (specifically from family and friends), and somewhat worse HRQOL, particularly as it pertains to pain, vitality, emotional interference in daily role functioning, and overall mental health than was evidenced by normative samples (MSPSS and WOC norms in Folkman \& Lazarus, 1988; PSS norms in Cohen et al., 1983; 
Table 1. A comparison of sample with national norms for the Perceived Stress Scale (PSS) ${ }^{\text {a }}$, Multidimensional Scale of Perceived Social Support (MPSSS) ${ }^{\mathrm{b}}$, Ways of Coping-Revised (WOC) ${ }^{\mathrm{c}}$, and Short Form-36 (SF-36) subscales ${ }^{\mathrm{d}}$.

\begin{tabular}{|c|c|c|c|}
\hline Measures & $\begin{array}{c}\text { Sample } \\
\text { mean (SD) }\end{array}$ & $\begin{array}{l}\text { Normative } \\
\text { mean (SD) }\end{array}$ & $\begin{array}{l}\text { Effect } \\
\text { size }\end{array}$ \\
\hline PSS & $16.53(5.8)$ & $12.0(5.6)$ & .80 \\
\hline MPSSS: TOTAL & $5.93(1.2)$ & $5.58(1.1)$ & .32 \\
\hline MPSSS: Family & $5.74(1.7)$ & $5.31(1.5)$ & .29 \\
\hline MPSSS: Friends & $5.98(1.5)$ & $5.50(1.3)$ & .37 \\
\hline MPSSS: Significant Others & $6.01(1.5)$ & $5.94(1.3)$ & .05 \\
\hline WOC: Confrontive Coping & $5.62(3.2)$ & $3.94(2.1)$ & .80 \\
\hline WOC: Distancing & $6.37(3.3)$ & $3.05(1.8)$ & 1.84 \\
\hline WOC: Self-Controlling & $9.33(4.0)$ & 5.77 (2.9) & 1.22 \\
\hline WOC: Seeking Social Support & $8.40(4.0)$ & $5.40(2.4)$ & 1.25 \\
\hline WOC: Accepted Responsibility & $4.36(3.0)$ & $1.87(1.4)$ & 1.78 \\
\hline WOC: Escape-Avoidance & $7.14(4.4)$ & $3.18(2.5)$ & 1.58 \\
\hline WOC: Planful Problem Solving & 9.39 (3.9) & $7.25(2.3)$ & .93 \\
\hline WOC: Positive Reappraisal & $8.57(4.4)$ & $3.48(3.0)$ & 1.70 \\
\hline SF-36: Physical functioning & $94.7(11.2)$ & $92.1(18.3)$ & .14 \\
\hline SF-36: Role-Physical & $85.7(25.0)$ & $89.1(26.8)$ & -.13 \\
\hline SF-36: Pain Severity ${ }^{\mathrm{e}}$ & $75.7(18.4)$ & $80.8(21.3)$ & -.24 \\
\hline SF-36: General Health & $74.1(17.2)$ & $76.7(18.2)$ & -.14 \\
\hline SF-36: Vitality & $56.8(17.3)$ & $62.5(19.8)$ & -.29 \\
\hline SF-36: Social Functioning & $80.4(20.0)$ & $83.9(20.6)$ & -.17 \\
\hline SF-36: Role-Emotional ${ }^{\mathrm{f}}$ & 68.4. (15.9) & $83.0(31.1)$ & -.47 \\
\hline SF-36: Mental Health Index ${ }^{\mathrm{g}}$ & $68.4(15.9)$ & $74.7(18.1)$ & -.35 \\
\hline SF-36: Physical Component Summary Scale ${ }^{\mathrm{h}}$ & $54.0(6.02)$ & $53.44(7.6)$ & .07 \\
\hline SF-36: Mental Health Component Summary Scale ${ }^{\mathrm{h}}$ & $44.7(10.4)$ & $49.1(10.2)$ & -.43 \\
\hline
\end{tabular}

${ }^{\mathrm{a}}$ PSS Norms are for 589 participants (1983) who had completed some college courses ${ }^{18}$. ${ }^{\mathrm{b}}$ MSPSS Norms are for 154 college students ${ }^{34}$. ${ }^{\mathrm{C}} \mathrm{WOC}$ Norms are for 150 upper-middle class participants ${ }^{34}$. ${ }^{\mathrm{d}}$ National norms for 18 - 24 years old males and females ${ }^{3}$. ${ }^{\mathrm{e}}$ Lower score on Pain Severity scale equals more pain-related disability ${ }^{3}$. $^{\mathrm{f}}$ Lower score on Role-Emotional scale equals more interference with daily functioning due to emotional problems ${ }^{3}$. ${ }^{\mathrm{g}}$ Lower score on Mental health scale equals greater feelings of nervousness and depression ${ }^{3}$. ${ }^{\mathrm{h}}$ Norms for Physical and Mental Health Composite Scales are for Males/Females ages $18-24^{31}$.

SF-36 norms in Ware, 1994); 2) over 50\% of the variance in MCS was accounted for by a combination of perceived stress and the use of escape avoidance, problem solving, and accepting responsibility coping strategies; and 3) psychosocial variables predicted a statistically significant amount of the variance in PCS, however, the practical importance of these predictions is negligible.

It is clear from these data that university students at a private 4-year university are experiencing significant amounts of perceived stress, are attempting to utilize a variety of coping strategies to manage it, and are experiencing HRQOL that is not as high as would be expected. Two points are worth discussion. First, the high PSS scores are consistent with findings from other recent studies investigating perceived stress among college students (Carson \& Runco, 1999; Hunter, 1998; Naquin \& Gilbert, 1996) and indicate that college students currently perceive their lives to be more stressful than was true when the original PSS norms were established in 1983. Why this is the case is unknown. One significant possibility has to do with the demographics of college 
Table 2. Stepwise-entry linear regression predicting the SF-36 Mental Health Component Summary Scale scores from stress, social support, and coping variables.

\begin{tabular}{cccccc}
\hline Variables & Standardized $\beta$ & $\mathrm{R}$ & $\mathrm{R}$-square change & $\mathrm{t}$ & $\begin{array}{c}p \text {-value for } \beta \text { in final } \\
\text { model }\end{array}$ \\
\hline Total stress & -.548 & .678 & $.460^{*}$ & -11.69 & .00 \\
Coping: escape avoidance & -.193 & .707 & $.039^{*}$ & -3.75 & .00 \\
Coping: problem solving & .108 & .711 & $.007^{*}$ & 2.49 & .01 \\
Coping: accepting responsibility & -.101 & .716 & $.007^{*}$ & -2.07 & .04 \\
(Constant) & & & & 36.56 & .00 \\
\hline
\end{tabular}

${ }^{*} p<.05$.

Table 3. Simultaneous-entry linear regression predicting the SF-36 Physical Health Component Summary scale scores from stress, social support, and coping variables.

\begin{tabular}{cccccc}
\hline Variables & Standardized $\beta$ & $\mathrm{R}$ & $\mathrm{R}$-square change & $\mathrm{t}$ & $\begin{array}{c}p \text {-value for } \beta \text { in final } \\
\text { model }\end{array}$ \\
\hline Coping: self-control & -.148 & .158 & $.025^{*}$ & -2.614 & .01 \\
Social support: family & -.114 & .195 & $.013^{*}$ & 2.017 & .04 \\
(Constant) & & & & 35.75 & .00 \\
\hline
\end{tabular}

${ }^{*} p<.05$.

attendance, notably the increasing number of females enrolling in college. Hunter (1998) demonstrated that females report more perceived stress than do males; consequently, as more females enter college overall stress scores for college students rise. This explanation, though logical, is inadequate because it leaves unaddressed the question of why females would perceive more stress than males. Many theories are possible. Females may simply be more likely to report stress. Findings in the mental health literature have consistently indicated that females are more open to acknowledging negative emotional states than are males. Hunter (1998) also suggested that females may: 1) suffer from outdated academic advising that is non-supportive when they are studying in areas typically dominated by males; 2) be more likely to face role conflict when attending college, and; 3) have more difficulty responding to evaluation pressure. Whatever the case, this area is certainly worthy of further study.

Other possible explanations for the increase in stress scores and worse mental health functioning include greater numbers of students holding outside employment during their college careers, an increasingly competitive job market, advancing technology that leaves students and others often feeling unable to maintain proficiency in current technologies, and an overall increasing body of knowledge in all fields of study, making it more difficult for students to master their subject area and forcing more choices for specialized study at earlier times during their college career. Relatedly, graduate study is becoming more necessary in many fields and thus there is increasing pressure to maintain high grade point averages so that admission to high caliber graduate programs may be secured.

A second interesting finding is that the students appear to be engaging in variety of coping strategies, including both those that have been found to be generally adaptive (e.g., problem solving) and those generally maladaptive. Even so, their stress scores remain high, suggesting that their coping methods are, at least to some extent, ineffective or inadequate. This conclusion is strengthened by noting the strong negative relation between perceived stress and mental health as measured by the SF-36, the unexpectedly poor reported mental health of these students, and by the finding that of the factors predicting overall poor mental health, two were maladaptive coping strategies (escape avoidance coping and accepting responsibility/self-blame coping).

These findings have some significant implications for college personnel working with students. It is important to understand that, by its nature, college is stressful (Fisher \& Hood, 1987). As a time of transition, college requires students to leave familiar environments, roles, and support systems and embark on a journey involving adaptation to multiple new challenges. Notable among these challenges are the many decisions that must be made pertaining to major field of study, selection of specific courses during particular terms, balance of time 
between social pressures and academic pursuits, whether to pursue graduate study, etc. Fazio and Powell (1997) demonstrated the value of students knowing their own likes and dislikes. Decision making can be facilitated by such self-understanding and insight. To the extent that college advisors and counselors can help students improve their understanding of their own values and motives, the students will be in a better position to make choices congruent with their own natures and thus likely reduce some of the stress inherent in these situations.

College is also stressful due to the continual presence of evaluation, often taking the form of tests of knowledge. Not only does testing raise questions for the student regarding his/her abilities but it also often carries with it a type of social pressure to perform well. Many students admit to feeling test anxiety. Interventions aimed at reducing this anxiety are important and should include training in test taking strategies, relaxation techniques, and cognitive interventions, as well as emphasis on improved study skills. The authors have found that simple overlearning of material is one of the best and most overlooked methods for reducing test anxiety.

Intervening with college students to reduce stress should begin early in their career before maladaptive coping strategies have become habitual. How can this be done? First, many universities now offer orientation weeks to freshmen that include stress management components. These are important and should emphasize the normative nature of stress at college and the availability of resources to assist in coping. Advanced students or peer counselors are a proven intervention method that should be readily available to all students but particularly those in their early days of college. Developing an early sense of self-efficacy is essential to successful college coping and will be greatly facilitated by these types of experiences. It should also be noted that college is not for everyone. Many students no doubt are stressed by spending day after day engaging in study that is of little interest to them and may even be incongruent with their personal goals and values. Interventions to help them find their proper niches are needed. This may sometimes include family counseling to deal with parental expectations regarding, for example, the parents' desire that their child receive a prestigious college degree. Finally, courses emphasizing adaptive coping skills that are contained within the college curriculum, offered early to students, and counting for credit toward their degree may help them develop necessary skills early in their training.

The SF-36 is a brief self-report that may be of particular value in a college health setting given its inclusion of both physical and mental health components along with its brevity. To justify adoption of this measure in college student health centers, further research is needed to confirm the elevated college norms found in the present study, in order to ensure accurate assessment of HRQOL for students. It is also important that research addresses physical health correlates of the SF-36 in this population.

The results of this study are limited in that this is the only study addressing correlates and norms of the SF-36 for a college student population. It is also possible that characteristics related to the institution whose students participated in this research are related to the results. Given that the university which was used in this study is fairly selective (DeBerard \& Julka, 2000) and generally enrolls students of higher socioeconomic status, the generalizability of these results to a broader college population is uncertain. Further research is needed to replicate these findings.

\section{Conclusion}

It is worth mention that the psychosocial variables studied in this research had a negligible ability to predict physical health. Since this was a young and relatively healthy sample, it is not surprising that predictions of physical health were limited in their magnitude. However, it is well-known that mental health and physical health are, in the long run, related. To the extent that interventions in college can enable students to develop better stress coping skills it is reasonable to conclude that these same skills will serve them well throughout the challenges of life and consequently reduce the likelihood of suffering from diseases or symptoms that are either caused or exacerbated by negative stress responding. If these interventions are not made available, the current data suggest that college students may turn into adults who are particularly prone to stress related disorders. In short, the college campus is an ideal time and setting for significant training in stress coping and management.

\section{References}

Arnoldus, J. H., Killestein, J., Pfennings, L. E., Jelles, B., Uitdehaag, B. M., \& Polman, C. H. (2000). Quality of Life during the First 6 Months of Interferon-Beta Treatment in Patients with M.S. Multiple Sclerosis, 6, 338-342.

Bastardo, Y. M., \& Kimberlin, C. L. (2000). Relationship between Quality of Life, Social Support and Disease-Related Factors in HIV-Infected Persons in Venezuela. AIDS Care, 12, 673-684. http://dx.doi.org/10.1080/095401200750003842 
Blumenthal, J. A., Burg, M. A., Barefoot, J., Williams, R. B., Haney, T., \& Zimet, G. (1987). Social Support, Type A Behavior, and Coronary Artery Disease. Psychosomatic Medicine, 49, 331-340. http://dx.doi.org/10.1097/00006842-198707000-00002

Bombardier, C. (2000). Outcome Assessments in the Evaluation of Treatment of Spinal Disorders: Summary and General Recommendations. Spine, 25, 3100-3103. http://dx.doi.org/10.1097/00007632-200012150-00003

Cohen S., \& Williamson, G. M. (1988). Perceived Stress in a Probability Sample in the United States. In: S. Spacapan, \& S. Oskamp (Eds.), The Social Psychology of Health. Newbury Park, UK: Sage.

Cohen, S., Doyle, W. J., \& Skoner, D. P. (1999). Psychological Stress, Cytokine Production, and Severity of Upper Respiratory Illness. Psychosomatic Medicine, 61, 175-180. http://dx.doi.org/10.1097/00006842-199903000-00009

Cohen, S., Frank, E., Doyle, W. J., Skoner, D. P., Rabin, B. S., \& Gwaltney, J. M. (1998). Types of Stressors That Increase Susceptibility to the Common Cold in Healthy Adults. Health Psychology, 17, 214-223. http://dx.doi.org/10.1037/0278-6133.17.3.214

Cohen, S., Kamarck, T., \& Mermelstein, R. (1983). A Global Measure of Perceived Stress. Journal of Health and Social Behavior, 24, 385-396. http://dx.doi.org/10.2307/2136404

Dahlem, N. W., Zimet, G. D., \& Walker, R. R. (1991). The Multidimensional Scale of Perceived Social Support: A Confirmation Study. Journal of Clinical Psychology, 47, 756-761. http://dx.doi.org/10.1002/1097-4679(199111)47:6<756::AID-JCLP2270470605>3.0.CO;2-L

Damush, T. M., Hays, R. D., \& DiMatteo, M. R. (1997). Stressful Live Events and Health-Related Quality of Life in College Students. Journal of College Student Development, 38, 181-190.

DeBerard, M. S., \& Julka, D. (2000). University of Portland Freshman Study. Unpublished Data, University of Portland.

DeBerard, M. S., Masters, K. S., Colledge, A., Schleusener, R., \& Schlegel, J. (2001). Outcomes of Posterolateral Lumbar Fusion in Utah Patients Receiving Workers' Compensation: A Retrospective-Cohort Study. Spine, 26, 738-747. http://dx.doi.org/10.1097/00007632-200104010-00007

Drossman, D. A., Leserman, J., Li, Z., Keefe, F., Hu, Y. J., \& Toomey, T. C. (2000). Effects of Coping on Health Outcome among Women with Gastrointestinal Disorders. Psychosomatic Medicine, 62, 309-317. http://dx.doi.org/10.1097/00006842-200005000-00004

Farup, C., Kleinman, L., Sloan, S., Ganoczy, D., Chee, E., Lee, C., \& Revicki, D. (2001). The Impact of Nocturnal Symptoms Associated with Gastroesophageal Reflux Disease on Health-Related Quality of Life. Archives of Internal Medicine, 161, 45-52. http://dx.doi.org/10.1001/archinte.161.1.45

Fazio, R. H., \& Powell, M .C. (1997). On the Value of Knowing One’s Likes and Dislikes: Attitude Accessibility, Stress, and Health in College. Psychological Science, 8, 430-436. http://dx.doi.org/10.1111/j.1467-9280.1997.tb00456.x

Fisher, S., \& Hood, B. (1987). The Stress of Transition to University: A Longitudinal Study of Psychological Disturbance, Absent-Mindedness, and Vulnerability to Homesickness. British Journal of Psychology, 78, 425-441. http://dx.doi.org/10.1111/j.2044-8295.1987.tb02260.x

Folkman, S. F., \& Lazarus, R. S. (1988). Ways of Coping Questionnaire Manual. Redwood City, CA: Consulting Psychologists Press, Inc.

Frazier, L. D. (2000). Coping with Disease-Related Stressors in Parkinson’s Disease. The Gerontologist, 40, 53-63. http://dx.doi.org/10.1093/geront/40.1.53

Glaser, R., Kiecolt-Glaser, J. K., Speicher, C. E., \& Holliday, J. E. (1985). Stress, Loneliness, and Changes in Herpesvirus Latency. Journal of Behavioral Medicine, 8, 249-260. http://dx.doi.org/10.1007/BF00870312

Gross, C. R., Limwattananon, C., Matthees, B., Zehrer, J. L., \& Savik, K. (2000). Impact of Transplantation on Quality of Life in Patients with Diabetes and Renal Dysfunction. Transplantation, 70, 1736-1746. http://dx.doi.org/10.1097/00007890-200012270-00013

Haas, B. K. (1999). A Multidisciplinary Concept Analysis of Quality of Life. Western Journal of_Nursing Research, 21, 728742. http://dx.doi.org/10.1177/01939459922044153

Hamalainen, H., Smith, R., Puukka, P., Lind, J., Kallio, V., Kuttila, K., \& Ronnemaa, T. (2000). Social Support and Physical and Psychological Recovery One Year after Myocardial Infarction or Coronary Artery Bypass Surgery. Scandanavian Journal of Public Health, 28, 62-70.

Hunter, R. D. A. (1998). Coping with Perceived Stress among College Students: Gender Differences, Coping Styles, and the Role of Alcohol, Tobacco, and Drug Use. Dissertation Abstracts International.

Kaplan, R. M. (1990). Behavior as the Central Outcome in Health Care. American Psychologist, 45, 1211-1220. http://dx.doi.org/10.1037/0003-066X.45.11.1211

Kennedy, S., Kiecolt-Glaser, J. K., \& Glaser, R (1988). Immunological Consequences of Acute and Chronic Stressors: Mediating Role of Interpersonal Relationships. British Journal of Medical Psychology, 61, 77-85. 
http://dx.doi.org/10.1111/j.2044-8341.1988.tb02766.x

Lee, S., Park, M., Choi, S., Nah, Y., Abbey, S. E., \& Rodin, G. (2000). Stress, Coping, and Depression in Non-Ulcer Dyspepsia Patients. Journal of Psychosomatic Research, 49, 93-99. http://dx.doi.org/10.1016/S0022-3999(00)00148-3

Leserman, J. (2000). The Effects of Depression, Stressful Life Events, Social Support, and Coping on the Progression of HIV Infection. Current Psychiatry Reports, 26, 495-502. http://dx.doi.org/10.1007/s11920-000-0008-4

Matsen, F. A., Antoniou, J., Rozencwaig, R., Campbell, B., \& Smith, K. L. (2000). Correlates with Comfort and Function after Total Shoulder Arthroplasty for Degenerative Joint Disease. Journal of Shoulder and Elbow Surgery, 9, 465-469. http://dx.doi.org/10.1067/mse.2000.109323

Moskovitz, D. N., Maunder, R. G., Cohen Z., McLeod R. S., \& MacRae, H. (2000). Coping Behavior and Social Support Contribute Independently to Quality of Life after Surgery for Inflammatory Bowel Disease. Diseases of the Colon and Rectum, 43, 517-521. http://dx.doi.org/10.1007/BF02237197

Naquin, M. R., \& Gilbert, G. G. (1996). College Students’ Smoking Behavior, Perceived Stress, and Coping Styles. Journal of Drug Education, 26, 367-376. http://dx.doi.org/10.2190/MTG0-DCCE-YR29-JLT3

Roberts, R., Golding, J., Towell, T., \& Weinreb, I. (1999). The Effects of Economic Circumstances on British Students' Mental and Physical Health. Journal of American College Health, 48, 103-109.

http://dx.doi.org/10.1080/07448489909595681

Roberts, R., Golding, J., Towell, T., Reid, S., Woodford, S., Vetere, A., \& Weinreb, I. (2000). Mental and Physical Health in Students: The Role of Economic Circumstances. British Journal of Health Psychology, 5, 289-297. http://dx.doi.org/10.1348/135910700168928

Rumsfeld, J. S., MacWhinney, S., McCarthy, M., Shroyer, A. L., VillaNueva, C. B., O’Brien, M., Moritz, T. E., Henderson, W. G., Grover, F. L., Sethi, G. K., \& Hammermeister, K. E. (1999). Health-Related Quality of Life as a Predictor of Mortality Following Coronary Artery Bypass Graft Surgery. Participants of the Department of Veterans Affairs Cooperative Study Group on Processes, Structures, and Outcomes of Care in Cardiac Surgery. Journal of the American Medical Association, 281, 1298-1303. http://dx.doi.org/10.1001/jama.281.14.1298

Stewart, A. L., \& Ware, J. E. (1992). Measuring Functioning and Well Being: The Medical Outcomes Study Approach. Durham and London: Duke University Press.

Tennant, C. (2000). Work Stress and Coronary Heart Disease. Journal of Cardiovascular Risk, 7, 273-276.

Ware, J. E., Snow, K. K., Kosinski, M. A., \& Gandek, M. S. (2000) SF-36 Health Survey: Manual and Interpretation Guide. Boston, MA: The Health Institute, New England Medical Center Hospitals.

Ware, J. E. (1994). SF-36 Physical and Mental Health Summary Scales: A User's Manual. Boston, MA: The Health Institute, New England Medical Center Hospitals.

World Health Organization (1948). International Classification of Impairments, Disabilities, and Handicaps: A Manual Classification Relating to the Consequences of Disease. Geneva: Author.

Zimet, G. D., Dahlem, N. W., Zimet, S. G., \& Farley, G. K. (1988). The Multidimensional Scale of Perceived Social Support. Journal of Personality Assessment, 52, 30-41. http://dx.doi.org/10.1207/s15327752jpa5201_2 